\title{
NON-SUBSTANCE ADDICTIONS IN THE CONTEXT OF INDIVIDUAL AND SOCIAL HEALTH
}

\author{
Roman Adamczyk
}

\begin{abstract}
The article deals with present-day non-substance-related (behavioral, process) addictions that interfere with the complex of individual and social health. Selected impacts of addiction onto the physical, mental and social level are discussed along with the interplay of addiction factors and health.
\end{abstract}

\section{Keywords}

non-substance addictions, behavioral addictions, individual health, social health

\section{Introduction and background}

Implementation of electronic communication and mobile technologies results in restructuring of social relationships and poses a new challenge in the form of emergence of previously unknown addictions and psychosocial phenomena, such as netholism (internet addiction) or nomophobia (the fear of mobile phone or coverage being unavailable). Therefore, new - behavioral-type - addictions accede to the "traditional" body of substance-related addictions that possess defined effects on the organism as desired by the user, e.g., euphoria, stimulation, sedation etc. The term 'new' addictions is to be understood as a relative one, since the category of non-substance addictions has been represented in the field across several decades, being exemplified by such entities as work addiction (workaholism), shopping addiction (shopaholism) or television addiction - Grant et al., 2010; Karim \& Chaudhri, 2012.

While the domain of substance addictions has been widely studied and elaborated in great detail in both academic and clinical settings for a number of decades and has been meticulously classified from the perspective of the substances used, non-substance (behavioral, process) addictions only won widespread nosological attention and became the topic of intense discussion in recent years. This expansion was conditioned by the development of infrastructures that constitute its prerequisites in the form of respective stimuli (easily accessible slot machines, computer networks, large-scale shopping centers etc.). Non-substance addictions not directly linked to technology and infrastructure, 
such as sexual addiction or the aforementioned work addiction, analogically constitute a part of the complex scope of addictive behavior (addiction disorders) that stem from immanent psychological impulses and needs irrespective of the material environs. Food addiction or addiction to a certain type of eating or dieting then represents a specific transition between non-substance-related addictive behavior and chemical stimulation as exerted by certain types of food within the frame of their psychoactive properties hand in hand with related symbolic and social status and other factors (chocolate, for instance, is a social symbol of relish and, simultaneously, a chemically active psychostimulant deriving its properties from caffeine, theobromine and phenylethylamine) - Smit, Gaffan, \& Rogers, 2004.

Both substance addictions and behavioral-type addictions influence the functioning of each individual per se and his/her quality of life, nevertheless, they combine with a significant outreach to the social environment of the person, his/her relationships and social health. Social health is defined as co-operative relations of an individual with his/her relatives and other persons in adjacent settings, the quality and intensity of relationships with other individuals, groups and institutions, the level of social support available, meaningful interactions with the social environment in various contexts, as well as the capacity to cope in typical social situations (Hahn et al., 2010). In her didactic concept of social health, Weare (2002) considers even a wider scope of implications in terms of maximization of life potential in a social setting that contributes to happiness, vigor and prevention of interpersonal conflicts. As Larkin (2011) emphasizes, the social dimension of health becomes increasingly important in recent decades and it is apparent that many health disturbances have social causes or co-factors on the one hand, and social impacts on the other hand.

\section{Classification, mechanisms and health/social aspects of non-substance addictions}

Classification of non-substance addictions is, to a certain extent, covered in current taxonomies, including the ICD (International Classification of Diseases in its $10^{\text {th }}$ version, with $11^{\text {th }}$ version under way - ÚZIS, 2008) and DSM (Diagnostic and Statistical Manual of Mental Disorders, currently in its $5^{\text {th }}$ revision - Raboch et al., 2015). However, it can be expected that existing taxonomies will be subject to further analysis, re-evaluations and expansions, based on changing conceptualizations along with the development of new technologies, such as virtual reality or artificial intelligence, that have the potential to evoke novel types of behavioral addiction. Current arrangement offers a limited number of possibilities to clinicians in terms of covering particular non-substance addictions. In DSM-V, the category of non-substance-related addictions comprises only a single explicit entity, namely, gambling disorder, i.e., pathological wagering (code 312.31). Annex to the DSM-V (Conditions for Further Study) mentions the proposed 'internet gaming disorder' warranting more research and it is likely that behavioral/process addictions will be subject to a more detailed taxonomy with multiple clinical units in the oncoming years (Raboch et al., 2015, p. 838-840). A separate coding category for on-line and off-line gaming disorder, distinct from gambling, is to be expected in ICD-11 in 2022. 
Non-substance addictions are reciprocally linked with the health status of the individual. Impaired health can act as an initiator or co-factor of addiction, possibly due to frustration of specific needs of the disabled or diseased person. Chemical changes in brain tissue may also participate in the etiology of addiction, necessitating broader considerations of not only psychological and social factors, but also biological variables. On the contrary, persisting addiction can disrupt the physical and mental health of a given individual, as well as his/her social health embedded in functioning relationships, job career and leisure activities. For addictive behavior to be fully understood, it is imperative to reflect both directions of the interactive mechanism between health and addiction.

The mechanisms of the negative impact of addiction on individual health can further be specified relative to the area of health being most significantly afflicted.

Firstly, the domain of physical (physiological and anatomical) health can be impacted by behavioral addictions. This can be documented by the recent Anglo-Saxon coinage 'text neck', referring to a form of strain syndrome related to prolonged forward flexion and alteration of the natural cervical lordosis, as caused by mobile phone overuse. Muscle imbalances also result from sustained use of computers, although the evidence for a direct relationship between the carpal tunnel syndrome and one-sided use of the computer mouse is weak (Shiri \& Falah-Hassani, 2015). The fear of a mobile phone or mobile phone network coverage being unavailable is semi-officially termed 'nomophobia' in clinical practice (etymologically derived from 'no mobile phone phobia'). In some cases, the technological addiction related to phones can take the shape of unreal, almost hallucinatory perceptions with the phone owner supposing there was a ring or vibration despite the objective absence of the latter stimulus (Stone, 2014). This type of technological addiction predominantly affects young persons aged 30 or less. The prevalence of mobile phone (smartphone) overuse ranks between 10-44 \% in the 11-14 teenage group in various countries (Davey \& Davey, 2014; Ong \& Tan, 2014). Weinstein and Lejoyeux (2010) report a range of internet addiction prevalence rates in European and American populations between 1.5 and $8.2 \%$, depending on the scales and criteria applied.

The ravages of technological and non-technological behavioral addictions on physical health depend on the nature of viscose (clinging) behavior and on the nature of the stimulus. Computer gaming addiction, either in its online or offline form, has been widely documented in, e.g., Japanese and Tchaiwanese youth and is accompanied by an increased risk of thrombotic events, impaired body posture, starving and dehydration, with the subjects being unable to stop or interrupt long-lasting engagement in playing (Yen et al., 2007; Park, Kim, \& Cho, 2008). In extreme cases, gaming records with uninterrupted, sustained play with no food intake have been reported with a duration of up to 40 hours or more, including fatal cases (Douglas, 2012). According to Ječmenová, whose empirical surveys focused on the time spent handling a computer among Czech junior high school students, approximately $1 / 3$ of boys and $15 \%$ of girls face the computer screen for three hours or more a day (Ječmenová, 2011).

Musculoskeletal disorders that emerge as sequelae of digital addictions include the repetitive strain injury, radial stenosing tendosynovitis (De Quervain syndrome) or 
impaired body posture (Ilyas et al., 2007). In food addiction and addiction to certain types of treats, short-term effects like nausea or hyperacidity can be expected, along with long-term effects connected with elevated saccharide or fat levels (cariogenesis, tendency to overweight, atherosclerosis). In shopaholism-like behavioral addictions, no such direct physical consequences would be anticipated, yet, they can have a marked impact in the economic and psychosocial domain (financial difficulties, hoarding as a source of conflict in the household etc.).

The effect of physical sequelae of behavioral addiction on social functioning and on the adjacent social environment, especially the family, is partly different from the effects of substance addictions and can involve temporary incapacity for work (a phenomenon otherwise occurring as a natural consequence of prolonged use of workplace technology, especially when incorrect postural stereotypes are present), functional limitations resulting from pain syndromes with possible curbing of activities of daily living (ADL's), self-sufficiency and social activities, and, finally, long-term disability in severe cases. In all the aforementioned instances, compensation of monotonous exertion is indicated, along with rehabilitation or physical therapy, as well as psychological support focusing on motivation and remodeling of existing stereotypes, e.g., in the form of cognitivebehavioral therapy (CBT).

Psychological sequelae of non-substance addictions constitute the second category of impacts of this type of addictive behavior and they can encompass the affective domain (mood changes when the addiction-provoking stimulus is unavailable), the anxiety disorder domain (increasing anxiety when the addiction-provoking stimulus is unavailable) and the personality domain (with alterations in volitional characteristics, shifts on the introversion-extraversion axis or restructuring of values and attitudes) - Dong et al., 2011. One of the less studied areas is that of emotional sequelae taking the shape of remorse and guilt. Since disturbances of autoregulation and impulse control are the common denominators of various types of addiction, specific compulsive phenomena may be observed. These could, however, had been a part of the pre-morbid personality (before the development of addiction sensu stricto), and, therefore, might have been one of the predisposing factors for the development of addiction and a part of its symptomatology, rather than a specific sequel.

As Marazziti et al. (2014) state, non-substance/behavioral addictions are, analogically to substance addictions, accompanied by significant social corrolaries. Investigation into social evaluation of behavioral addictions compared to substance addictions indicates that, despite certain similar social impacts, the respective two types of addiction are perceived differently. For example, Konkoly et al. (2015) surveyed a representative sample of 4,000 Canadian respondents and concluded that attributions of substance addictions (alcohol, tobacco, cocaine) are mostly oriented toward the robust biochemical potential of the substance causing addiction, while the etiology of process addictions (gambling, shopaholism, videogaming, workaholism etc.) is predominantly interpreted as related to the moral profile and character (suspected flaws of the character) of the addicted person. Unfortunately, this kind of attribution leads to stigmatization of the behaviorally addicted and, possibly, poses an obstacle to treatment seeking. Since 
Konkoly et al. realized their survey on a macro-level in the general population, it is arguable to what extent can their findings be applied to the level of the family as a small social group with tight interpersonal bonds. In close relationships, the stigmatizing labelling of a process addiction can be replaced by the phenomenon of benevolence, a well-known occurrence among alcohol addicts, whose relatives are often inclined to overt tolerance or justification of drinking and related antisocial phenomena despite the obvious negative psychosocial consequences of abuse.

The impact of behavioral addictions usually extends beyond the individual. In some instances, they may result in social withdrawal, in other cases they may initiate new social connections, many of which, however, do not foster social health (gangs, virtualized relationships in on-line gaming and social network overuse, volatile or harmful relationships). Apart from social withdrawal, social disinhibition with promiscuous behavior can become problematic. Besides, economic implications present a challenge in those addictions that entail major financial expenditures and the burden of poverty and debts is often carried by the whole family.

Contemporary mobile and computer technologies represent a crucial factor of peer relationships, being largely used especially by younger generations for prompt interaction with classmates or workmates. Despite undoubted benefits of this type of communication there exist a number of risks linked to the urge for 'being on-line all the time', resulting in tension and excessive stress levels - such as in the case of the aforementioned nomophobia. Further, there exist risks connected with the ousting of other activities when the majority of time is invested in on-line chatting, messaging (communication programs), telephoning or texting (SMS). Also, social networks and messengers are gradually taking the role of a new bullying platform that can disrupt peer relationships, as well as teacher-pupil or parent-child relationships. The parent-child dyad involves basic trust by the parent toward the child and vice versa. Once the child's or adolescent's electronic communication with peers, listening to recordings or other technology-related activities reach the level of addiction, the parent is edged out of the relationship territory and, hence, loses one of his/her fundamental emotional bonds.

Technological addictions can foster sibling rivalry, e.g., competing for computer time when the number of computers in the household is lower than the number of siblings. At the same time, siblings may mutually facilitate their addictive behaviors by simultaneous (shared) playing of on-line games or overusing communication software and hardware. To mitigate the negative image of technology, we should concurrently be aware of its potential for social health support and for the maintenance of parental or sibling relationships, e.g., in prolonged periods of separation due to job or study in places distant from home. Additionally, the internet is a source of information about itself, offering certain knowledge of technological addictions and, thus, providing opportunities for endangered individuals to become aware of the need for change and to find basic recommendations on how to handle situations indicative of detrimental physical, psychological and/or social impacts related to a particular stereotypical behavior, including internet addiction. 


\section{Conclusion}

Non-substance (behavioral, process) addictions constitute an undesirable element of current developments related to changes in the society at large and to widespread availability of modern technology. They share certain features with substance-related addictions, yet, simultaneously, evince a number of specific properties. A subset of sequelae in social health and individual health, either physical or mental/emotional, are fairly comparable. Nevertheless, to date, non-substance-related addictions are only marginally categorized in existing major classification systems (ICD, DSM). Further refinements of this issue can be expected in the future.

Both individuals and the society as such should strive to comprehend the mechanisms of behavioral addiction and make effort to reduce its impact on the individual level (physical health, prevention of affective and anxiety disorders), relationship level and societal macro-level (incapacity for work, financial burden placed on the health care system, social pathology). Strategies available for tackling this issue include addiction therapy, cognitive-behavioral therapy, social work and, to a limited extent, certain types of medication. Moreover, brand new approaches and interventions can be developed to better accommodate for the specific characteristics of emerging technological and nontechnological addictions.

\section{References}

Davey, S., \& Davey, A. (2014). Assessment of Smartphone Addiction in Indian Adolescents: A Mixed Method Study by Systematic-review and Meta-analysis Approach. International Journal of Preventive Medicine, 5(12), 1500-1511.

Dong, G., Lu, Q., Zhou, H., \& Zhao, X. (2011). Precursor or Sequela: Pathological Disorders in People with Internet Addiction Disorder. PLoS One, 6(2), e14703.

Douglas, A. (2012). Taiwanese Teen Dies after Playing 40 Consecutive Hours. Retrieved June 11, 2019, from http://www.businessinsider.com/taiwanese-teen-dies-after-playing40-consecutive-hours

Grant, J. E., Potenza, M. N., Weinstein, A., \& Gorelick, D. A. (2010). Introduction to Behavioral Addictions. American Journal of Drug and Alcohol Abuse, 36(5), 233-241.

Hahn, E. A., Devellis, R. F., Bode, R. K., Garcia, S. F., Castel, L. D., Eisen, S. V., .. Group, O. B. (2010). Measuring Social Health in the Patient-reported Outcomes Measurement Information System (PROMIS): Item Bank Development and Testing. Quality of Life Research, 19(7), 1035-1044. 
Ilyas, A., Ast, M., Schaffer, A. A., \& Thoder, J. (2007). De Quervain Tenosynovitis of the Wrist. Journal of the American Academy of Orthopaedic Surgeons, 15(12), 757-764.

Ječmenová, M. (2011). Fenomén netholismu u žáků 2. stupně základních škol na Príbramsku [Phenomenon of Netholism in Pupils of the Second Stage of Primary Schools in Příbram Area] (diploma thesis). České Budějovice: Jihočeská univerzita v Českých Budějovicích, Zdravotně sociální fakulta.

Karim, R., \& Chaudhri, P. (2012). Behavioral Addictions: An Overview. Journal of Psychoactive Drugs, 44(1), 5-17.

Konkolÿ, T. B., Colman, I., el-Guebaly, N., Hodgins D. C., Patten, S. B., Schopflocher, D., ... Wild, T. C. (2015). Social Judgments of Behavioral Versus Substance-related Addictions: A Population-based Study. Addictive Behaviors, 42, 24-31.

Larkin, M. (2011). Social Aspects of Health, Illness and Healthcare. Maidenhead: Open University Press.

Lopez-Fernandez, O., Honrubia-Serrano, L., Freixa-Blanxart, M., \& Gibson, W. (2014). Prevalence of Problematic Mobile Phone Use in British Adolescents. Cyberpsychology, Behavior and Social Networking, 17(2), 91-98.

Marazziti, D., Presta, S., Baroni, S., Silvestri, S., \& Dell'Osso, L. (2014). Behavioral Addictions: A Novel Challenge for Psychopharmacology. CNS Spectrum, 19(6), 486-495.

Ong, S. H., \& Tan, Y. R. (2014). Internet Addiction in Young People. Annals of the Academy of Medicine, Singapore, 43(7), 378-382.

Park, S. K., Kim, J. Y., \& Cho, C. B. (2008). Prevalence of Internet Addiction and Correlations with Family Factors among South Korean Adolescents. Adolescence, 43(172), 895-909.

Raboch, J. (Ed.) et al. (2015). DSM-5®: Diagnostický a statistický manuál duševních poruch. Praha: Hogrefe - Testcentrum.

Shiri, R., \& Falah-Hassani, K. (2015). Computer Use and Carpal Tunnel Syndrome: A Meta-analysis. Journal of Neurological Sciences, 349(1-2), 15-19.

Smit, H. J., Gaffan, E. A., \& Rogers, P. J. (2004). Methylxanthines Are the Psychopharmacologically Active Constituents of Chocolate. Psychopharmacology, 176(3-4), 412-419.

Stone, M. (2014). Smartphone Addiction Now Has A Clinical Name. Retrieved June 11, 2019, from http://www.businessinsider.com/what-is-nomophobia-2014-7 
ÚZIS. Ústav zdravotnických informací a statistiky České republiky [Institute of Health Information and Statistics of the Czech Republic]. (2008). Mezinárodní statistická klasifikace nemocí a přidružených zdravotních problémů: $M K N-10$ : desátá revize: aktualizovaná druhá verze k 1. 1. 2009. Tabelární část. Praha: Bomton Agency.

Weare, K. (2002). Promoting Mental, Emotional and Social Health: A Whole School Approach. London: Routledge.

Weinstein, A., \& Lejoyeux, M. (2010). Internet Addiction or Excessive Internet Use. American Journal of Drug and Alcohol Abuse, 36(5), 277-283.

Yen, J. Y., Yen, C. F., Chen, C. C., Chen, S. H., \& Ko, C. H. (2007). Family Factors of Internet Addiction and Substance Use Experience in Taiwanese Adolescents. Cyberpsychology \& Behavior, 10(3), 323-329.

\section{Author}

Mgr. Bc. Roman Adamczyk, Ph.D.

Faculty of Public Policies in Opava, Silesian University in Opava Institute of Nursing

Bezručovo nám. 885/14, 74601 Opava, Czech Republic roman.adamczyk@fvp.slu.cz 